\title{
Understanding and Interpretation: Defending Gadamer in light of Shusterman's "Beneath Interpretation"
}

\author{
Scott R. Stroud
}

San José State University

\section{Introduction}

Hans-Georg Gadamer's important work, Truth and Method, ushered in a new trend in hermeneutic thought that combined understanding, interpretation, and application into a dynamic process that all individuals experience in actions producing meaning. The individual was portrayed as situated in a specific tradition that influences the cognitions and meanings that texts and language use in general can contain. The central point of Gadamer's hermeneutic thought is that the human being is historically situated, and that understanding is consequently historically conditioned. It was this intrinsic situatedness of humans and their prejudices that led him to conclude, "all understanding is interpretation."

Richard Shusterman, in his work "Beneath Interpretation," has recently taken issue with this stance that equates interpretation with understanding, arguing for a conception of "understanding" that resides "beneath" interpretation. Gadamer and others are said to collapse interpretation into understanding, thus depriving understood bodily experiences of their place in the conceptualization of "understanding." According to Shusterman, all understanding does not involve interpretation. This essay will argue that this position advanced by Shusterman rests ultimately on a misconception of Gadamer's notion of interpretation, and as such, is not a strong challenge to Gadamer's insights concerning the process of human understanding. Shusterman's emphasis on understanding being pre-reflective and interpretation being conscious disavows Gadamer's analysis that they are identical in so far as they both refer to an individual's situatedness in tradition and its concurrent impacts on the production of meaning. In order to demonstrate how this is so, this essay will first examine some of 
Shusterman's key arguments and conceptualizations in regard to the "hermeneutic universalism" espoused by individuals such as Gadamer. The ways that the Gadamerian notion of understanding can be maintained in light of Shusterman's critique will be illustrated. In all, Gadamer's notion of understanding will be shown to highlight the role of the traditional "prejudices" always given to the subject that inform his or her acts of understanding; this "substratum" to any act of understanding/interpretation will in turn be seen to facilitate the acts of understanding Shusterman points to as counterexamples.

\section{Shusterman on Understanding and Interpretation}

Shusterman's argument aims at establishing a ground of understanding that rests beneath the level of cognitive interpretation. In his essay, "Beneath Interpretation," Shusterman refutes six arguments that the hermeneutic universalist (such as Gadamer) present in arguing that all understanding is interpretation. The fourth and fifth arguments are of particular interest to this inquiry, since they address the selective and active nature of interpretation. Shusterman attempts to show that these arguments are faulty in that they do not demonstrate that understanding as active/selective follows from an identical sense of interpretation as active/selective. Instead, he indicates that this establishes the ground for a new conceptualization of these two terms.

Shusterman points out that an important hermeneutic argument is that "since all understanding is selective-focused on some things and features but not others-all understanding must therefore be interpretive." The aspects of incompleteness and purposive orientation are indicated as prime culprits in the in the ultimate perspectivity of understanding, thus rendering it the same as interpretation. Interpretation, as Shusterman previously notes, is constituted by differing perspectives and certain purposes, and hence is seen as "grasp[ing that]" which "depends in part on its antecedent purposes." The hermeneutic universalist finds that all understanding, like interpretation, is motivated by purpose and a certain perspective of the subject. 
It is at this point that Shusterman disagrees with the conflation of understanding with interpretation. He "challenge[s] the inference that since understanding (or indeed any intelligent activity) is always selective, it is therefore always interpretation." This is claimed to be an instance of John Dewey's "intellectualist" fallacy, which argues that it is overly reductionistic to equate intelligent human activity to overt acts of intellectual consciousness. Shusterman counters this trend by suggesting that many daily activities one undertakes are "intelligent," but lack any in-depth interpretation. For instance, where to place one's feet on a staircase or on the sidewalk are intelligent activities toward some goal that do not rely on overt, conscious processes of deliberation. Additionally, he provides the example of his awakening on the beach of Santa Cruz and immediately perceiving or understanding it is daytime due to the bright sunshine. He summarizes this position by stating,

I am arguing that though all understanding is selective, not all selective understanding is interpretive. If understanding's selection is neither conscious nor deliberate but prereflective and immediate, we have no reason to regard that selection or the resultant understanding as interpretation, since interpretation standardly implies some deliberate or at least conscious thinking, whereas understanding does not.

The response Shusterman provides to this line of thinking already prefaces his conceptualization of understanding as beneath the active forces of interpretation.

Related to this argument is the hermeneutic position that since all understanding is active, it is interpretation. Shusterman sees such a line of thought in thinkers such as Nietzsche and Gadamer. Relying on physiological activity in the mere reception of stimuli, Shusterman finds that these thinkers posit all understanding as activity, and that this warrants the judgment that all understanding is interpretation. This argument, according to Shusterman, "relies on an implicit premise that all 'doings' that are cognitively valuable or significant for thought are themselves already cases of thinking." Instead, this presupposition is rejected in favor of understanding's 
activity being based in non-thought involving activities. Shusterman provides an example yet again from the sunny climes of Santa Cruz, indicating that when someone tells him "the surf is up" while he is on the way to the beach, no need for interpretation exists. It is "only if there where some problem in understanding, some puzzle or doubt or incongruity, would I have to thematize the utterance as something that needed interpretation, something to think about and clarify or resolve." While Shusterman continues on to answer the challenge to this position that all experience is linguistically conditioned, his point is clear; understanding should be conceived of as involving intelligent activities that are different from the reflective act of understanding.

It is at this point that some of the general distinctions between Shusterman's conceptions of understanding and interpretation can be broached. Understanding is seen as that which "initially grounds and guides interpretation, while the later explores, validates, or modifies that initial ground of meaning." Understanding is thus portrayed as the unconscious but intelligent action that is occurring in non-reflective acts of linguistic comprehension or immediate sensuous intuition, whereas "interpretation" is said to be a better label for the "conscious and problem-solving character" of interpretative activity. Shusterman indicates that while "both are inevitably perspectival, interpretive activity seems intrinsically aware that alternative interpretations may be given to resolve a problem, while understanding can be unreflectively blind to the existence or possibility of alternative understandings, since it can be unaware of any problem of understanding that might present alternative solutions." Drawing on the insights of Wittgenstein, Shusterman seems to be arguing that the reflective dimension of consciousness is the primary criterion by which understanding should be distinguished from interpretation. Highlighting that certain intelligent activities are prereflective, Shusterman extends Wittgenstein's notion of behavioral training in specific "game" contexts as accounting for the grounding of understanding that underlies interpretation. Shusterman indicates that "Understanding, on the other hand, does not require linguistic articulation. A proper reaction, a shudder or tingle, may be enough to indicate one has understood," whereas interpretation aims at translating linguistic 
expressions into other meaningful ones. Gadamer's notion of all understanding being interpretation is hence challenged, since some understanding is seen as putatively non-interpretative and unconscious.

\section{Gadamerian Responses to Shusterman}

Gadamer's analysis of understanding as interpretation can be defended from Shusterman's criticism. Looking at his conceptualization in Truth and Method, one notices that Shusterman is mistaking what Gadamer's project is accomplishing; Shusterman is arguing that the common notion of interpretation is radically different from the non-conscious but cognitively valuable operations he highlights, whereas Gadamer is postulating that the factors of activity and selectivity are constitutive of historical being. Thus, the understanding of such a being is the same as interpretation, with each instance of such understanding/interpretation differing in how much temporal distance is crossed, for example, in reading an ancient text or a contemporary conversation. This section will defend Gadamer's position against Shusterman's critique by drawing from the discussions of prejudices and historical effect/ application resident in Truth and Method.

Shusterman's conception of understanding as beneath interpretation holds it as an unconscious, yet cognitively valuable act. Thus, Gadamer's notion of interpretation and understanding being equivalent is challenged. Shusterman's argument, however, relies on the premise that interpretation must be a conscious and reflective event. While this concurs with common parlance of this term, it misses the thrust of Gadamer's claims-the very core of meaning is produced by the individual in relation to his or her situatedness. Whether this production and schematizing is called by the words "understanding" or "interpretation," the same point of selection and activity from a specific perspective is implied. A key notion in this historical situatedness is the subject's "prejudices." These tendencies toward "prejudgment" stem from an individual's place in a specific tradition. This leads Gadamer to pronounce, "Understanding is to be thought of less as a subjective act than as participating in an event of tradition, a process of 
transmission in which past and present are constantly mediated." Thus, the individual is not to be looked at as simply an absorber of incoming stimuli, but as a participant wading deeply in the midst of a tradition.

This tradition is conveyed not only through conscious interaction on the part of the individual, as Shusterman appears to imply, but is also often pre-reflective. In a similar vein, Gadamer notes that understanding (equivalent to interpretation in his view) can be non-reflective; he argues, "Long before we understand ourselves through a process of self-examination, we understand ourselves in a self-evident way in the family, society, and state in which we live." These pre-conscious elements are key to any act of understanding/interpretation; contra Shusterman, Gadamer refrains from equating interpretation with conscious activity because that would reify a relatively minor element. He indicates, "The self-awareness of the individual is only a flickering in the closed circuits of historical life. That is why the prejudices of the individual, far more that his [sic] judgments, constitute the historical reality of his being." The prejudicial structure of understanding is the important aspect, not the mere consciousness or self-awareness of any particular individual. The socialization, linguistic culture, and tradition that the individual finds him or herself occupying all lead to the conscious and unconscious assignment of meaning, hence understanding. To use Shusterman's example, it is the tradition of verbal and nonverbal communication that he finds in himself that leads to the recognition of the phrase "the surf is up" and his consequential response. While he does not cogitate overtly on the meaning of the semantic units of this utterance, he does recognize and understand its meaning through his immersion in a language and cultural tradition. What he discounts as Wittgensteinian training and pre-reflective understanding, Gadamer rightly finds as still interpretive because it involves prejudices from a particular tradition in order for it to hold meaning for the specific individual addressed. Shusterman need only say this same utterance to an Australian Aborigine to see if it is understood. While such a counterexample may seem unfair to Shusterman's position (as he accepts the role of culture and linguistic socialization), it does fairly point out the role of the 
traditional prejudices in assigning meaning. Whether it is a complex novel or a routine utterance, Gadamer argues that one's historical situatedness is key in the meanings that are evident or available. Whether it involves deliberation and self-consciousness misses Gadamer's point; the important aspect is the role of tradition in influencing the creation of meaning by an individual participating in that very tradition.

The previous response began to touch upon another aspect to Gadamer's thought that Shusterman fails to address - the integral part that subjective positioning plays in interpretation. The individual, through prejudices and location in a tradition, finds him or herself conditioned by the past; Gadamer notes, "in all understanding, whether we are expressly aware of it or not, the efficacy of history is at work." This "history of effect" or "effective history" is an important concept in Truth and Method and can be applied to the defense of Gadamer against Shusterman's criticism. The past does influence the future and the ways that the future looks at the past. To the "beach bum" looking for waves to surf, the historical use of language and behavior effects what meanings are addressed now and how those meanings may remain open to future change. Gadamer notes that "Understanding is, essentially, a historically effected event" and by doing so acknowledges the traditional aspect to the very conception of meaning. When one understands a past text or communicative utterance, one seeks its meaning in application to the present. For instance, Gadamer refers to the case of legal and theological interpretation, stating, "This implies that the text, whether law or gospel, if it is to be understood properly -i.e., according to the claim it makes—-must be understood at every moment, in every concrete situation, in a new and different way. Understanding here is always application." The reason why understanding of any sort involves application is because it is initiated by an individual saturated by and within a tradition, which in turn confronts an object (i.e., text) that is also immersed in tradition.

Shusterman's examples of linguistic utterances and the piercing rays of the sun on the Santa Cruz beach both illustrate not his point that understanding and interpretation are different, but instead that they are both aligned toward the production of meaning with a 
sense of present application. The individual approaching the beach "understands" the utterance from the fellow individual since he or she is mired in tradition and orients him or herself toward present meaning; the "text" of the utterance is seen as possessing meaning because its interpretation involves application to the present situation of the individual approaching the beach. What Shusterman counts as radically different from Gadamer's analysis, actually supports the hermeneutic universalist position. The "pre-reflective" status of the understanding of the approaching surfer does not show that understanding is beneath interpretation, but instead that it is equivalent with this concept in that they both point toward the same practice-the effect of historical situatedness on an individual's meaning-making activities. The other example of sunshine striking Shusterman and making him immediately "aware" that he was in Santa Cruz and not Berlin also illustrates this point; the meaning of such stimuli come not from their mere occurrence, but instead from the individual qua traditionary influences assigning them meaning. To speak of one as "understanding" sunshine striking his or her eyes relies on a very shallow notion of understanding; instead, what one understands or interprets are the implications (near and far) of this "fact"-i.e., one must still be in a sunny location, he or she is laying on my back, it is day, etc. Notice that this sense of understanding can be either reflective or unreflective, and that it involves the application of some encountered object (text, phenomenon, utterance) to an individual's current situation. Gadamer's position still withstands the counterexamples and arguments of Shusterman-the important aspect to understanding and interpretation is that it is stationed in tradition and always involves application to a subject's current situation.

While Gadamer's arguments for the saturation of experience by language can also meet Shusterman's objections, this line of thought has been explicated elsewhere. What is important is the imposed criterion of consciousness/reflection that Shusterman uses to differentiate understanding from interpretation; this imposition ignores the key insight of Gadamer's thought, which is the application and situatedness of understanding/interpretation. By separating these two concepts and calling for one (understanding) to be used as the "given" data for reflective interpretation, 
Shusterman fails to see that unconscious or conscious productions of meaning occur situated in tradition and involve application to a concrete present, such as a conversational partner headed toward the beach. The sense of "understanding" that Shusterman advances only avoids these Gadamerian insights by being so non-cognitive that it loses the notion of understanding. If one's trained behavior of stepping down a flight of stairs or of attaining a certain posture compromises instances of "understanding," the term begins to lose its connotation of meaning. One's footwork or stance are not meanings as much as they are actions that can be linguistically evaluated. For instance, a dancer only understands that his or her posture is correct by knowing what it means in relation to past performances, present success, theory of balance, etc. At one point, when Shusterman argues that "Understanding, on the other hand, does not require linguistic articulation. A proper reaction, a shudder or tingle, may be enough to indicate one has understood," one wonders what sense of "understanding" is invoked in mere bodily movements. Notice that this example, congruent with current nonverbal communication research, states that these bodily movements can "indicate" understanding, but are not constitutive of understanding. What is understood or interpreted in this example is the meaning of these bodily reactions; one is applying a certain action in the immediate past to the present state of the conversation and its future directions. While Shusterman has brought up some interesting criticisms of Gadamer's position, his distinction between understanding and interpretation fails to hold as it avoids Gadamer's key insights - the meaning produced by an individual is conditioned by the activity/selectivity engendered by his or her placement in a tradition and its consequent prejudices.

\section{Notes}

' Hans-Georg Gadamer, Truth and Method (New York: Continuum, 1997); Cf Joseph Margolis, "Interpretation at Risk" (The Monist, 73, 312330) and Tom Rockmore, "Epistemology as Hermeneutics: Antifoundationalist Relativism" (The Monist, 73, 115-133).

${ }^{2}$ Ibid., 350. 
${ }^{3}$ Richard Shusterman, Pragmatist Aesthetics: Living Beauty, Rethinking Art, $2^{\text {nd }}$ ed. (Maryland: Rowman \& Littlefield, 2000); Performing Live: Aesthetic Alternatives for the Ends of Art (New York: Cornell University Press, 2000).

${ }^{4}$ Reprinted in Performing Live: Aesthetic Alternatives for the Ends of Art (New York: Cornell University Press, 2000, 115-136).

${ }^{5}$ Ibid., 124.

${ }^{6}$ Ibid., 124.

${ }^{7}$ Ibid., 124.

8 Ibid., 125.

${ }^{9}$ Ibid., 125.

${ }^{10}$ Ibid., 125.

"Ibid., 126.

${ }^{12}$ Ibid., 134.

13 Ibid., 134.

${ }^{14}$ Ibid., 135.

${ }^{15}$ Shusterman, Performing Live, 135.

${ }^{16}$ Gadamer, Truth and Method, 290, emphasis in original.

${ }^{17}$ Ibid., 276.

${ }^{18}$ Ibid., 276-277, emphasis in original.

${ }^{19}$ Ibid., 301.

${ }^{20}$ Ibid., 300.

${ }^{21}$ Ibid., 309.

${ }^{22}$ Cf. Jean Grondin, Introduction to Philosophical Hermeneutics (New Haven: Yale University Press, 1994) and Richard J. Bernstein, Beyond Objectivism and Relativism: Science, Hermeneutics, and Praxis (Philadelphia: University of Pennsylvania Press, 1996).

${ }^{23}$ Shusterman, Performing Live, 135.

${ }^{24}$ Judee K. Burgoon, David B. Buller, \& W. Gill Woodall, Nonverbal Communication: The Unspoken Dialogue (Columbus, Ohio: Greyden Press, 1994). 